\title{
Impact of Renal Impairment on Coronary Vasculature among Patients Undergoing Primary Percutaneous Coronary Intervention and its Effect on Hospital Stay Outcome
}

\author{
MAHMOUD M. KHALIL, M.Sc.; MEDHAT M. ASHMAWY, M.D.; MOHAMED W. EL-SETIHA, M.D. and \\ MAHMOUD A. ABOUOMAR, M.D. \\ The Department of Cardiovascular Medicine, Faculty of Medicine, Tanta University, Tanta, Egypt
}

\begin{abstract}
Background: The decrease in glomerular filtration rate is independently associated with increase of cardiovascular disease and cardiovascular death. Cardiovascular causes, mainly myocardial infraction are responsible for half of deaths in Chronic Kidney Disease (CKD) patients.
\end{abstract}

Aim of Study: To study impact of renal impairment on coronary vasculature among patients undergoing primary PCI and its effect on hospital stay outcome.

Methods: A prospective observational study conducted from June 2016 to November 2016, at Cardiovascular Medicine Department, Tanta University Hospitals in Gharbia Governorate, Egypt. The study enrolled 138 consecutive adultpatients of both genders who were diagnosed with definite STsegmentelevation myocardial infarction within 12 hours from the time ofsymptoms onset and were treated by primary percutaneous coronaryintervention. EGFR was calculated and the patient were divided into four groups according to the severity of the renal impairment.

Results: The current study showed that reduced renal function either estimated by eGFR was associated with significantly lower rates of suboptimal perfusion assessed by angiographic and by electrocardiographic criteria.Both the epicardial coronary artery flow and the myocardial perfusion were both reduced with reduced renal function when compared to the group with normal kidney functions.

Conclusion: CKD is not uncommon finding among patients with STEMI and the rate of no reflow showed significant increment with worsening of renal function. Both epicardial coronary flow and myocardial perfusion are reduced in CKD patients with STEMI and CKD was independently and inversely associated with the rate of procedural success.

Key Words: Chronic kidney disease - Percutaneous coronary intervention - ST elevation myocardial infarction - Primary percutaneous coronary intervention.

Correspondence to: Dr. Mahmoud M. Khalil, The Department of Cardiovascular Medicine, Faculty of Medicine, Tanta University, Tanta, Egypt

\section{Introduction}

MYOCARDIAL Infarction with persistent ST Segment Elevation (STEMI) is responsible for significant morbidity and mortality worldwide. According to the GRACE study $38 \%$ of patients presented with acute coronary syndrome have STEMI [1].

The prevalence of Chronic Kidney Disease (CKD) among patients with STEMI is 30\% [2] The decrease in glomerular filtration rate is independently associated with increase of cardiovascular disease and cardiovascular death. Cardiovascular causes, mainly myocardial infraction are responsible for half of deaths in CKD patients [3]

Renal function, atherothrombosis extent, and outcomes in high-risk patients (REACH) registry showed that the number of arterial beds affected increased with severity of CKD. However, patients with severe CKD were less likely to receive medications of proven benefit. Severe CKD was an independent correlate of all-cause mortality, cardiovascular mortality, myocardial infarction, congestive heart failure, peripheral arterial revascularization and amputation [4]

The ANIN registry is a single center prospective all-comer registry conducted at the Institute of Cardiology in Warsaw, included all STEMI patients treated with primary PCI, demonstrated that any decrease in renal function was associated with adverse outcomes including 30-days mortality, major bleeding and procedural failure even with normal serum creatinine. It was recommended that estimated Glomerular Filtration Rate (eGFR) should be considered a continuous parameter, which 
influences prognosis of STEMI patients without any specific cut-off value [5]

\section{Patients and Methods}

The study was conducted as observational study from June 2016 to November 2016, at Cardiovascular Medicine Department, Tanta University Hospitals in Gharbia Governorate, Egypt.

The study included 138 consecutive adult patients of both genders who were diagnosed with definite STEMI within 12 hours from the time of symptoms onset and were treated by primary PCI. An informed consent was taken from allparticipants.

Patients included in this study fulfilled all of the following criteria of acute myocardial infarction:

- Persistent anginal chest pain lasting for more than 20 minutes.

- ST-segment elevation of $>1 \mathrm{~mm}$ in two or more standard leads or $2 \mathrm{~mm}$ in two or more contiguous precordial leads, or the presence of new left bundle branch block.

- Primary percutaneous intervention with clear angiographic data enough to enable evaluation of the severity of coronary artery disease.

\section{Exclusion criteria were:}

Patients who received thrombolytic therapy.

All included patients were subjected to detailed history taking and clinical examination including measurement of vital signs and detection of signs of heart failure/hemodynamic instability according to Killipclassification.

Surface eelectrocardigram and venous sampling for laboratory data, includingserum cardiac biomarkers (cardiac troponin I \& CKMB), complete blood count, lipid profile, random blood sugar, urea $\&$ creatinine, were done.

All included patients were subjected to primary PCI for the Infarct Related Artery (IRA) according to the European Society of Cardiology (ESC) guidelines. Coronary angiography was performed under local anesthesia fromthe femoral approach according to the standard technique, and the following data is gathered:

Pain to door and door to balloon time, the culprit vessel, the presence or absence of other vessels affection and number of vessels affected and severity of CAD assessed by Gensini score as follows:

The points were assigned according to the percentage of luminal narrowing: 1 point for $1 \%$ $25 \%$ occlusion, 2 for $26 \%-50 \%$, 4 for $51 \%-75 \%$, 8 for $76 \%-90 \%, 16$ for $91 \%-99 \%$, and 32 points for a complete occlusion. Each of these points are compounded by multiplications factors accounting for the differences in the location of obstruction, such as 5 for left main artery, 2.5 for proximal left anterior descending and left circumflex arteries, and 1 for proximal right coronary artery.

Finally, the total Gensini score for each patient was expressed as the sum total score of each CAD lesion [6].

The intervention details including use of thrombus aspiration, Percutaneous Transcatheter Coronary Angioplasty (PTCA) with or without stent placement or direct stenting and type of stent used.

Occurrence of no reflow and any procedural complication were recorded including dissection and perforation.

The initial TIMI flow and Myocardial Blush Grade (MBG) were assessed initially, immediately after stent placement and at the end of the procedure by the operating cardiologist. Myocardial blush grading was performed visually in the catheterization lab on a cinefilmat 25 frames/second. No digital techniques were applied. Assessment of myocardial blush grade was done in the same views for the infarct related artery for standardization and for minimizing superimposition of noninfarcted territories in the assessment of the MBG. The left lateral view was used to assess lesions involving the left coronary artery while the right anterior oblique view was used to asses lesions involving the right coronary artery.

\section{TIMI classification used was:}

TIMI 0 (no perfusion): No antegrade flow beyond the point of occlusion.

TIMI 1 (penetration without perfusion): The contrast material passes beyond the area of obstruction but "hangs up" and fails to opacify the entire coronary bed distal to the obstruction for the duration of the cine angiographic filming sequence.

TIMI 2-(partial perfusion): The contrast material passes across the obstruction and opacifies the coronary bed distal to the obstruction. However, the rate of entry of contrast material into the vessel distal to the obstruction or its rate of clearance from the distal bed (or both) are perceptibly slower 
than its entry into or clearance from comparable areas not perfused by the previously occluded vessel-e.g., the opposite coronary artery or the coronary bed proximal to the obstruction.

TIMI 3-(complete perfusion): Antegrade flow into the beddistal to the obstruction occurs as promptly as antegrade flow into the bed proximal to the obstruction, and clearance of contrast material from the involved bed as rapid as clearance from an uninvolved bed in the same vessel or the opposite artery [7].

\section{Myocardial Blush Grade (MBG) used was:}

Grade 0: No myocardial blush or contrast density.

Grade 1: Minimal myocardial blush or contrast density.

Grade 2: Moderate myocardial blush or contrast density but less than that obtained during angiography of a contralateral or ipsilateral non-infarctrelated coronary artery.

Grade 3: Normal myocardial blush or contrast density, comparable with that obtained during angiography of a contralateral or ipsilateral noninfarct-related coronary artery $[8]$.

Procedural outcome assessed by:

A- Final TIMI flow.

B- Final MBG.

C- Successful reperfusion defined angiographicaly as TIMI 3 flow with MBG $\geq 2$ (Steg at, 2012) or electro-cardiographic by ST-segment resolution $\geq 70 \%$ within 4 hours following the procedure (Sorajja et al., 2005).

The studied patients were divided according to eGFR into:

Group 1: Normal renal function group (eGFR $\geq 90 \mathrm{~mL} / \mathrm{min} / 1.73 \mathrm{~m}^{2}$ ).

Group 2: Mild renal impairment (eGFR 60-89 $\mathrm{ml} / \mathrm{min} / 1.73 \mathrm{~m}^{2}$ ).

Group 3: Moderate renal impairment (eGFR $30-59 \mathrm{ml} / \mathrm{min} / 1.73 \mathrm{~m}^{2}$ ).

Group 4: Sever renal impairment (eGFR $<30$ $\mathrm{ml} / \mathrm{min} / 1.73 \mathrm{~m}^{2}$ ). (National Kidney Foundation, 2002).

eGFR was estimated using MDRD formula:

$\mathrm{eGFR}=186 \mathrm{X}$ (serum creatinine) $-1.154 \mathrm{X}$ age -0.0203 (X 1.210 if black) (X 0.742 if female).
Statistical presentation and analysis of the present study was conducted, using the mean, standard deviation and chi-square test by SPSS V.20. Numerical data was presented as mean and Standard Deviation (SD) and categorical data was presented as number and percentage. Chi-squared test was used for statistical analysis. When the chisquared test was not appropriate, the likelihood ratio test was applied. The level of significance was adopted at $p<0.05$.

Subjects were informed about the purpose and procedure of the study and benefits of sharing in it. Ethical considerations of the study were carried out according to that of Declaration of Helsinki [9].

\section{Results}

The studied patients were divided according to eGFR into Group I which included 25 patients with mean \pm SD age $49.5 \pm 9.07$ and 22 were male and 3 were female. Diabetes was present in 9 patients and hypertension was observed in 21 patients, Group II include 55 patients with mean age 56 and 43 were male and 12 were female, and diabetes was present in 32 patients and hypertension was observed in 37 patients, Group III was 43 patients with mean age 64 and 25 were male and 18 were female diabetes was present in 31 patients and hypertension was observed in 26 patients, Group IV was 15 patients with mean age 58 and 12 were male and 3 were female diabetes was present in 6 patients and hypertension was observed in 8 patients. Tables $(1,2)$.

Table (3) reveals that systolic blood pressure levels were as the following: $137.0 \pm 26.2 \mathrm{mmHg}$ in Group I, $135.5 \pm 23.9 \mathrm{mmHg}$ in Group II, 136.7 \pm $28.3 \mathrm{mmHg}$ in Group III, and $86.0 \pm 21.9 \mathrm{mmmHg}$ in Group IV. The diastolic blood pressure levels were as the following; $82.8 \pm 14.7 \mathrm{mmHg}$ in Group I, $80.8 \pm 14.4 \mathrm{mmHg}$ in Group II, $82.4 \pm 15.0 \mathrm{mmHg}$ in Group III, and $40.0 \pm 10.0 \mathrm{mmHg}$ in Group IV. The eGFR level had a statistically significant effect on systolic and diastolic blood pressure.

Regarding the Creatinine Clearance $(\mathrm{CrCl})$ level, it had the following means; $0.92 \pm 0.11$ in Group I, $1.0 \pm 0.1$ in Group II, $1.5 \pm 0.4$ in Group III, and 3.7 \pm 1.5 in Group IV. The differences in creatinine clearance levels between groups were statistically significant. The Contrast Induced Nephropathy (CIN) had the highest percentage in Group IV (80\%), followed by Group III (62.8\%), then Group II (30.9\%), and lastly Group I (4\%). The occurrence in CIN was statistically significant as regards the eGFR groups. 
The Initial Killip class IV had the highest percentage in Group IV (33.3\%). The difference in Killip class distribution among EGFR groups was statistically significant.

Table (4) shows that three vessels affection was the highest among Group IV (33.3\%). Regarding two vessels affection, the highest percentage was also among Group IV. One vessel affection was the highest among Group I (60\%). However, that difference wasn't statistically significant.

Group IV had the highest vessel affection level as regards $\mathrm{LAD}$, and $\mathrm{RCA}$, and $\mathrm{CX}(80 \%, 73.3 \%$, and $73.3 \%$, respectively). EGFR level had a statistically significant effect on the affected vessel $(p=0.001 *)$. Subgroup analysis revealed that Group IV, Group III, and Group II were statistically significant different when compared to other groups.

No statistically significant difference was observed in the number of affected vessels, the use of G2P, and pain to door time as regards EGFR level.

Table (5) shows that all patients in Group IV had intial TIMI score "0". The eGFR had no statistically significant effect on the theintial TIMI score $(p=0.192)$.

As regards the final TIMI score, Group IV represented the highest percentage of TIMI score grade 1 followed by group Group III (20\% and $9.3 \%$, respectively). The eGFR had a statistically significant effect on the final TIMI grade. eGFR level had a statistically significant effect on the final TIMI grade. The subgroup analysis revealed that Group IV had a statistically significant difference from the remaining groups $(p=0.001)$.
Table (6) showed the severity of coronary lesions by Gensisni score among the eGFR groups the result was statistically significant with highest among Group IV with mean \pm SD $106.9 \pm 24.8$ and $67.55 \pm 34.36$ in Group III and 52.54 \pm 28.6 in Group II and 50.68 \pm 24.3 in Group I.

Table (7) showed that there was statistically significant difference between the MBG between the four groups, Group IV showed the lowest MBG with $40 \%$ grade 0 and $46.7 \%$ grade 1 while Group III showed $11 \%$ grade $0,32 \%$ grade 1 and $39.5 \%$ grade 2 and $16 \%$ grade 3 Group II showed 5\% grade $0,29 \%$ grade $1,38 \%$ grade 3 and $27 \%$ grade 3 Group I showed $0 \%$ grade 0 and $8 \%$ grade 1 and $28 \%$ grade 2 and $64 \%$ grade 3 .

Regarding the systolic functions of the study patients, Group IV had the lowest ejection fraction\% mean \pm SD $(42.07 \pm 10.51)$. The eGFR had a statistically significant effect on the ejection fraction $(p=0.002)$, subgroups analysis showed that Group III (moderate renal dysfunctions) and Group IV (severe renal dysfunction) had statistically significant lowest value of systolic functions from other groups $(p=0.001 *)$.

Table (9) reveals that Group IV had the highest complication rate as the following; dialysis was indicated in $33.3 \%$, hemorrhage occurred in $13.3 \%$ of Group IV, and death occurred in 40\%. Regarding recurrent MI, it occurred in one case representing $2.3 \%$ of Group III.

Table (1): Distribution of the study patients into groups according to EGFR.

\begin{tabular}{llll}
\hline Study groups & EGFR & n. & $\&$ \\
\hline Group I & $>90$ & 25 & 18.1 \\
Group II & $60-89$ & 55 & 39.9 \\
Group III & $30-59$ & 43 & 31.2 \\
Group IV & $<30$ & 15 & 10.9 \\
\hline
\end{tabular}

Table (2): Demographic and risk factors of the eGFR groups.

\begin{tabular}{|c|c|c|c|c|c|c|}
\hline Variables & $\begin{array}{l}\text { Group I } \\
(\mathrm{n}=25)\end{array}$ & $\begin{array}{c}\text { Group II } \\
(\mathrm{n}=55)\end{array}$ & $\begin{array}{c}\text { Group III } \\
(\mathrm{n}=43)\end{array}$ & $\begin{array}{c}\text { Group IV } \\
(\mathrm{n}=15)\end{array}$ & $\begin{array}{l}\text { Sig. } \\
\text { test }\end{array}$ & $p$. \\
\hline $\begin{array}{l}\text { Age: } \\
\quad \text { Mean } \pm \text { S.D }\end{array}$ & $49.56 \pm 9.07$ & $56.42 \pm 10.27$ & $64.09 \pm 8.98$ & $58.73 \pm 10.65$ & F 12.413 & $0.001 *$ \\
\hline $\begin{array}{l}\text { Sex: } \\
\quad \text { Male } \\
\text { Female }\end{array}$ & $\begin{array}{lr}22 & (88.0 \%) \\
3 & (12.0 \%)\end{array}$ & $\begin{array}{l}43(78.2 \%) \\
12(21.8 \%)\end{array}$ & $\begin{array}{l}25(58.1 \%) \\
18(41.9 \%)\end{array}$ & $\begin{array}{l}12(80.0 \%) \\
3(20.0 \%)\end{array}$ & $\chi^{2} 8.930$ & $0.030 *$ \\
\hline DM & $9 \quad(36.0 \%)$ & $32(58.2 \%)$ & $31(72.1 \%)$ & $6(40.0 \%)$ & $\chi 210.255$ & $0.017 *$ \\
\hline HTN & $21(84.0 \%)$ & $37(67.3 \%)$ & $26(60.5 \%)$ & $8(53.3 \%)$ & $\chi 25.333$ & 0.149 \\
\hline Smoking & $19(76.0 \%)$ & $32(58.2 \%)$ & $24(55.8 \%)$ & $4(26.7 \%)$ & $\chi_{2} 9.379$ & $0.025^{*}$ \\
\hline
\end{tabular}


Table (3): Vital data and renal function of the studied groups.

\begin{tabular}{|c|c|c|c|c|c|c|}
\hline Variables & $\begin{array}{c}\text { Group I } \\
(n=25)\end{array}$ & $\begin{array}{c}\text { Group II } \\
(\mathrm{n}=55)\end{array}$ & $\underset{(n=43)}{\text { Group III }}$ & $\begin{array}{c}\text { Group IV } \\
(\mathrm{n}=15)\end{array}$ & $\begin{array}{l}\text { Sig. } \\
\text { test }\end{array}$ & $p$ \\
\hline \multicolumn{7}{|l|}{$S B P:$} \\
\hline Mean \pm S.D & $137.0 \pm 26.2$ & $135.5 \pm 23.9$ & $136.7 \pm 28.3$ & $86.0 \pm 21.9$ & $\mathrm{~F}$ & $0.001 *$ \\
\hline Comparing groups & $p_{1} 0.575$ & $p_{2} 0.585$ & $p_{3} 0.001 *$ & $p_{4} 0.001 *$ & 17.180 & \\
\hline \multicolumn{7}{|l|}{$D B P:$} \\
\hline Mean \pm S.D & $82.8 \pm 14.7$ & $80.8 \pm 14.4$ & $82.4 \pm 15.0$ & $40.0 \pm 10.0$ & $\mathrm{~F}$ & $0.001 *$ \\
\hline Comparing groups & $p_{1} 0.542$ & $p_{2} 0.587$ & $p_{3} 0.001^{*}$ & $p_{4} 0.001^{*}$ & 8.114 & \\
\hline \multicolumn{7}{|l|}{ Pulse: } \\
\hline Mean \pm S.D & $84.7 \pm 16.6$ & $82.09 \pm 16.4$ & $87.6 \pm 17.9$ & $81.6 \pm 21.8$ & F 0.926 & 0.430 \\
\hline \multicolumn{7}{|l|}{$\mathrm{Cr} C L \mathrm{ml} / \mathrm{min}:$} \\
\hline Mean \pm S.D & $0.92 \pm 0.11$ & $1.0 \pm 0.1$ & $1.5 \pm 0.4$ & $3.7 \pm 1.5$ & $\mathrm{~F}$ & $0.001 *$ \\
\hline Comparing groups & $p_{1} 0.326$ & $p_{2} 0.001 *$ & $p_{3} 0.001^{*}$ & $p_{4} 0.001 *$ & 95.875 & \\
\hline CIN: & $1(4 \%)$ & $17(30.9 \%$ & $27(62.8 \%)$ & $12(80.0 \%)$ & $x^{2}$ & $0.001 *$ \\
\hline Comparing groups & $p_{1} 0.435$ & $p_{2} 0.001 *$ & $p_{3} 0.001^{*}$ & $p_{4} 0.001^{*}$ & 34.259 & \\
\hline \multicolumn{7}{|l|}{ Initial Killip class: } \\
\hline I & $19(76.0 \%)$ & $44(80.0 \%)$ & $30(69.8 \%)$ & $1(6.7 \%)$ & $x^{2}$ & $0.001 *$ \\
\hline II & $6 \quad(24.0 \%)$ & $10(18.2 \%)$ & $11(25.6 \%)$ & $5(33.3 \%)$ & 68.295 & \\
\hline III & $0(0 \%)$ & $1 \quad(1.8 \%)$ & $2(4.7 \%)$ & $4(26.7 \%)$ & & \\
\hline IV & $0(0 \%)$ & $0(0 \%)$ & $0(0 \%)$ & $5(33.3 \%)$ & & \\
\hline Comparing groups & $p_{1} 0.520$ & $p_{2} 0.566$ & $p_{3} 0.001 *$ & $p_{4} 0.001^{*}$ & & \\
\hline \multicolumn{7}{|c|}{$\begin{array}{ll}{ }^{*}: \text { Statistically significant. } & p_{3}: \text { For comparing between Group III and Group IV. } \\
\chi^{2}: \text { Chi square test. } & p_{4}: \text { For comparing between Group I and Group IV. } \\
\mathrm{F}: \text { One way Analysis of Variance (ANOVA). } & \text { SBP }: \text { Systolic Blood Pressure. } \\
\text { Significance between groups by post Hoc LSD. } & \text { DBP : Diastolic Blood Pressure. } \\
p 1: \text { For comparing between Group I and Group II. } & \mathrm{CIN}: \text { Contrast Induced Nephropathy. } \\
p 2: \text { For comparing between Group II and Group III. } & \mathrm{CrCl}: \text { Creatinineclearence. }\end{array}$} \\
\hline
\end{tabular}

Table (4): Interventional data among the studied groups,

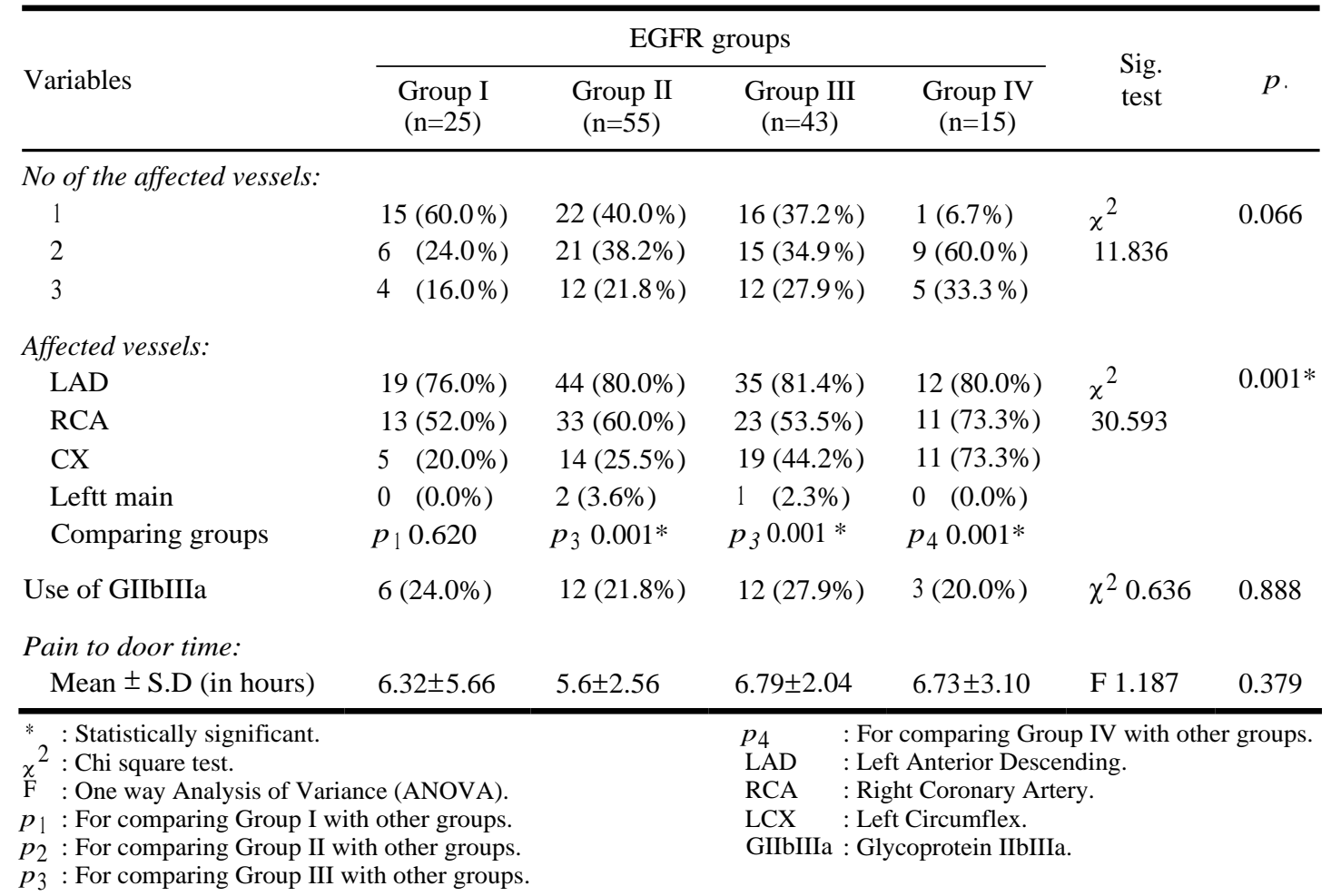


Table (5): TIMI score before and after PCI among the studied groups.

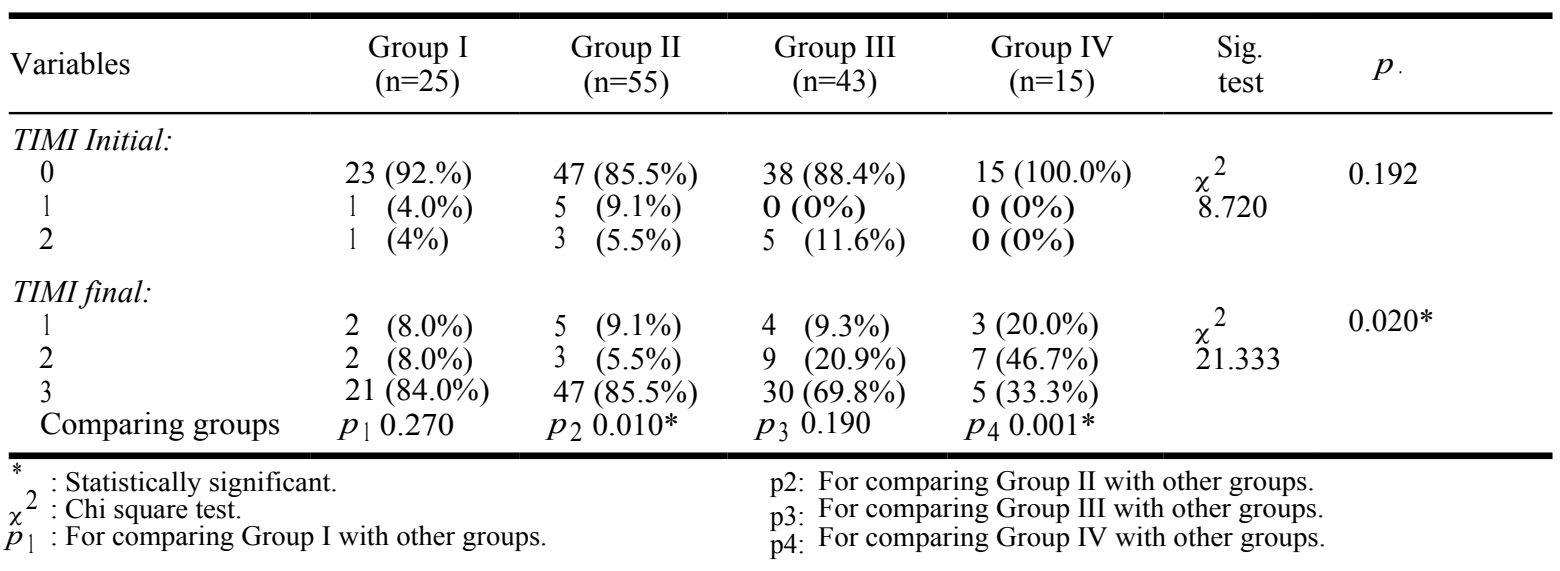

Table (6): Gensini score among EGFR groups.

\begin{tabular}{|c|c|c|c|c|c|c|}
\hline Gensini score & $\begin{array}{l}\text { Group I } \\
(n=25)\end{array}$ & $\begin{array}{l}\text { Group II } \\
(\mathrm{n}=55)\end{array}$ & $\begin{array}{l}\text { Group III } \\
(\mathrm{n}=43)\end{array}$ & $\begin{array}{l}\text { Group IV } \\
(\mathrm{n}=15)\end{array}$ & $\begin{array}{l}\text { Sig. } \\
\text { test }\end{array}$ & $p$ \\
\hline $\begin{array}{l}\text { Mean } \pm \text { S.D } \\
\text { Comparing groups }\end{array}$ & $\begin{array}{l}50.68 \pm 24.3 \\
p_{1} 0.795\end{array}$ & $\begin{array}{l}52.54 \pm 28.6 \\
p_{2} 0.014^{*}\end{array}$ & $\begin{array}{l}67.55 \pm 34.36 \\
p_{3} 0.001^{*}\end{array}$ & $\begin{array}{l}106.9 \pm 24.8 \\
p_{4} 0.001 *\end{array}$ & 5.204 & $0.002 *$ \\
\hline
\end{tabular}

* : Statistically significant.

$\mathrm{F}$ : One way Analysis of Variance (ANOVA).

Significance between groups by post Hoc LSD

p1. For comparing between Group I and Group II.

p2: For comparing between Group II and Group III.

p3: For comparing between Group III and Group IV. p4: For comparing between Group I and Group IV.

Table (7): MBG grade among the studied groups.

\begin{tabular}{lccccc}
\hline MBG grade & $\begin{array}{c}\text { Group I } \\
(\mathrm{n}=25)\end{array}$ & $\begin{array}{c}\text { Group II } \\
(\mathrm{n}=55)\end{array}$ & $\begin{array}{c}\text { Group III } \\
(\mathrm{n}=43)\end{array}$ & $\begin{array}{c}\text { Group IV } \\
(\mathrm{n}=15)\end{array}$ & $\begin{array}{c}\text { Sig. } \\
\text { test }\end{array}$ \\
\hline 0 & $0(0.0 \%)$ & $3(5.5 \%)$ & $5(11.6 \%)$ & $6(40.0 \%)$ & $\chi^{2}$ \\
1 & $2(8.0 \%)$ & $16(29.1 \%)$ & $14(32.6 \%)$ & $7(46.7 \%)$ & 43.721 \\
2 & $7(28.0 \%)$ & $21(38.2 \%)$ & $17(39.5 \%)$ & $2(13.3 \%)$ & \\
3 & $16(64.0 \%)$ & $15(27.3 \%)$ & $7(16.3 \%)$ & $0(0.0 \%)$ & \\
Comparing groups & $p_{1} 0.379$ & $p_{2} 0.010 *$ & $p_{3} 0.019 *$ & $p_{4} 0.001 *$ & \\
\hline
\end{tabular}

* : Statistically significant. $\quad p_{3}$ : For comparing Group III with other groups.

$\chi^{2}:$ Chi square test.

$p_{1}$ : For comparing Group I with other groups.

$p_{2}$ : For comparing Group II with other groups.

$p_{4}$ : For comparing Group IV with other groups.

MBG : Myocardial Blush Grade.

Table (8): Ejection fraction among the studied groups.

\begin{tabular}{|c|c|c|c|c|c|c|}
\hline Variables & $\begin{array}{l}\text { Group I } \\
(n=25)\end{array}$ & $\begin{array}{l}\text { Group II } \\
(\mathrm{n}=55)\end{array}$ & $\begin{array}{l}\text { Group III } \\
(\mathrm{n}=43)\end{array}$ & $\begin{array}{l}\text { Group IV } \\
(\mathrm{n}=15)\end{array}$ & $\begin{array}{l}\text { Sig. } \\
\text { test }\end{array}$ & $p$ \\
\hline $\begin{array}{l}\text { Ejection fraction \%: } \\
\text { Mean } \pm \text { S.D } \\
\text { Comparing groups }\end{array}$ & $\begin{array}{l}54.17 \pm 7.44 \\
p_{1} 0.520\end{array}$ & $\begin{array}{l}50.55 \pm 9.39 \\
p_{2} 0.566\end{array}$ & $\begin{array}{l}51.60 \pm 10.42 \\
p_{3} 0.001 *\end{array}$ & $\begin{array}{l}42.07 \pm 10.51 \\
p_{4} 0.001^{*}\end{array}$ & 5.204 & $0.002 *$ \\
\hline
\end{tabular}

Table (9): Distribution of complication among the studied groups.

\begin{tabular}{|c|c|c|c|c|c|c|}
\hline \multirow[b]{2}{*}{ Variables } & \multicolumn{4}{|c|}{ EGFR groups } & \multirow[b]{2}{*}{$x^{2}$} & \multirow[b]{2}{*}{$p$} \\
\hline & $\begin{array}{l}\text { Group I } \\
(\mathrm{n}=25)\end{array}$ & $\begin{array}{l}\text { Group II } \\
(\mathrm{n}=55)\end{array}$ & $\begin{array}{c}\text { Group III } \\
(\mathrm{n}=43)\end{array}$ & $\begin{array}{c}\text { Group IV } \\
(\mathrm{n}=15)\end{array}$ & & \\
\hline Dialysis & $0(0 \%)$ & $0(0 \%)$ & $0(0 \%)$ & $5(33.3 \%)$ & 42.541 & $0.001 *$ \\
\hline Hemorrhage & $1(4 \%)$ & $3(5.5 \%)$ & $0(0 \%)$ & $2(13.3 \%)$ & 5.036 & 0.169 \\
\hline Death & $0(0 \%)$ & $3(5.5 \%)$ & $4(9.3 \%)$ & $6(40.0 \%)$ & 20.053 & $0.001 *$ \\
\hline Recurrent MI & $0(0 \%)$ & $0(0 \%)$ & $1(2.3 \%)$ & $0(0 \%)$ & 2.225 & 0.527 \\
\hline
\end{tabular}

*: Statistically significant. 


\section{Discussion}

In patients with Acute Coronary Syndrome (ACS), CKD represents a potent and independent risk factor for adverse outcomes. Although the mechanism of such adverse outcomes is not completely understood, it is believed to be due to interaction between extensive comorbidities and traditional risk factors which are highly prevalent in the CKD patients' population and the unique pathology of CKD [10]

This work enrolled patients admitted to Tanta University Hospitals by STEMI and treated by primary PCI from June 2016 to December 2016 to evaluate the effect of CKD on the angiographic outcomes in those patients.

Among CKD patients, the majority were males. They were older than the group with normal renal functions with significantly higher proportion of females when compared to the normal renal function group. This can be attributed to the gradual decline of renal function which is a recognized feature of the aging process despite presence of wide variability in the rate of decline among individuals [11]

This agrees with Kim et al., [12] who found that among patients undergoing primary PCI, CKD patients were older and more likely to be females.

The current study showed significant difference in prevalence of smoking among different groups. This agree with, Polanska-Skrzypczyk et al., (2013) [5] who stated that CKD patients were less likely to have a positive history of smoking.

Hypertensions as well as DM were more prevalent with progressive decline in kidney functions. The relationship between high blood pressure and kidney disease is complex [13]. This can be attributed to hypertension being a risk factor for CKD and a contributor to its progression (Toto, 2005) [14], or the development of hypertension as a consequence of CKD. Decrements in renal function is associated with parallel increments in arterial blood pressure [14]

Among the patients with reduced renal function, only $23 \%$ were known to be CKD. Owing to the nature of CKD being asymptomatic and clinically silent till its late stages [15]. The current study showed that the Initial Killip class IV had the highest percentage in Group IV (33.3\%). The difference in Killip class distribution among EGFR groups was statistically significant. This agrees with the findings of Polanska-Skrzypczyk et al.,
(2013) [5] and Kim et al., (2010) who found that patients with CKD had a significantly higher killip class on admission.

The location of STEMI in CKD group was not significantly different when compared the normal renal function group with Anterior STEMI representing around $60 \%$ of cases in both groups.

Polanska-Skrzypczyk et al., [5] demonstrated that decline of renal function didn't have an effect on localization of STEMI although non-anterior infarction was more common in both normal renal function group and CKD group.

On the contrary Kim et al., (2010) [12] demonstrated that with decline in the renal function the left anterior descending artery became less involved with more involvement of the right coronary artery.

There was also a non-significant trend towards a longer pain to door time in patients with CKD. This can be explained by frequent absence of classic symptoms of ischemia in CKD patients which delays seeking medical attention [16].

Compared to the general population, CKD patients experience a more dramatic progression of coronary artery disease with higher rate of atypical presentations [17]

Silent or atypical presentations of acute coronary syndromes in CKD can be attributed to higher prevalence of diabetes in this population [13]. It is estimated that the prevalence of silent myocardial infarction was $13 \%$ compared with $4 \%$ in those without CKD [14]. It was found that patients on regular dialysis who were hospitalized for acute myocardial infarction experienced chest pain less frequently than those who are not on dialysis [18]

With progressive worsening of renal function, there was an increase in the number of major coronary arteries involved in the atherosclerotic process and the severity of the CAD.

The current study showed that with progressive worsening of renal function, there was an increase in the severity of CAD.

This agrees with the findings of Yagi et al., [19] who evaluated the relationship between the severity of Coronary Artery Disease (CAD) assessed by Gensini score and traditional coronary risk factors, metabolic syndrome, and Chronic Kidney Disease (CKD) in patients undergoing elective coronary angiography. Comparing the prevalence of risk factors between patients with single vessel disease and patients with multivessel disease, it was 
demonstrated that CKD was the only independent predictor of multivessel disease. Patients with CKD had a 2.9 fold risk of having multivessel disease.

Kim et al., [12] retrospectively evaluated the records of 1192 patients who underwent elective coronary angiography; the severity of CAD was evaluated by Gensini score. Reduced renal function was an independent predictor of both the prevalence and the severity of coronary artery disease even after controlling for traditional cardiovascular risk factors including diabetes, hypertension and dyslipidemia.

Furthermore, Coskun el al., [20] demonstrated that even among patients with multivessel disease, the decline in kidney function is directly proportional to the complexity of coronary artery lesions assessed by the syntax score.

The current study showed that reduced renal function either estimated by eGFR was associated with significantly lower rates of suboptimal perfusion assessed by angiographic and by electrocardiographic criteria. Both the epicardial coronary artery flow and the myocardial perfusion were both reduced with reduced renal function when compared to the group with normal kidney functions.

As regards the final TIMI score, Group IV represented the highest percentage of TIMI score grade 3 followed by group Group III (20\% and $9.3 \%$, respectively). The EGFR had a statistically significant effect on the final TIMI score. EGFR level had a statistically significant effect on the final TIMI score. The subgroup analysis revealed that Group IV had a statistically significant difference from the remaining groups ( $p=0.001)$.

Presence of CKD was associated with lower rates of TIMI flow and MBG assessed at the end of the procedure.

After controlling for covariates both eGFR calculated by MDRD formula was independently and inversely associated with suboptimal perfusion following primary PCI. This goes hand in hand with the findings of Sabroe et al., (2014) [21] who evaluated the impact of CKD on angiographic and clinical outcomes in 4116 patients undergoing 1ry PCI for treatment of STEMI. Patients were divided to two groups with a cutoff $\mathrm{CrCl}$ of $60 \mathrm{ml} / \mathrm{min}$. Although the initial TIMI flow was similar in both groups the final TIMI flow was significantly lower in the renal insufficiency group. The reduction in $\mathrm{CrCl}$ was an independent predictor of mortality. This is in accordance with the findings of Kim et al., (2010) [12] who found that in patients with moderate and severe renal dysfunction rates of optimal reperfusion (defined as finalTIMI 3 flow) were significantly lower with progressive decline in renal function.

A prospective single center study conducted by Polanska-Skrzypczyk et al., [5] at the Institute of Cardiology in Warsaw (Anin) where all consecutive patients with STEMI treated with 1ry PCI between February 2001 and October 2002 were included in a prospective registry demonstrated an association between CKD and procedural failure defined as TIMI flow <3. After adjustment for covariates independent predictors of procedural failure were decreased eGFR, initial TIMI flow $<2$ and a positive history of smoking.

Kurtul et al., [22] assessed the relationship between renal dysfunction and no re-flow phenomenon in 673 patients undergoing primary PCI, demonstrated that declining renal function together with higher killip class at presentation and left ventricular ejection fraction as independent predictors of suboptimal perfusion.

The association between on admission eGFR and poor myocardial perfusion was assessed in 80 patients with STEMI treated by primary PCI. Patients were stratified by TIMI Myocardial Perfusion Grade (TMPG). Reduced eGFR together with peak CKMB, left ventricular ejection fraction less than $35 \%$, initial TIMI flow grade $<2$ and longer painto-balloon time were independently associated with poor myocardial perfusion [23] .

In the current study that Group IV had the highest complication rate as the following; dialysis was indicated in $33.3 \%$, hemorrhage occurred in $13.3 \%$ of Group IV, and death occurred in $40 \%$. Regarding recurrent MI, it occurred in one case representing $2.3 \%$ of Group III.

The eGFR level had a statistically significant effect on dialysis and death among the study patients.

This agree with Polanska-Skrzypczyk et al., (2013) [5] who state the rate of complication is higher among CKD group and Kim et al., [12] who also stated that rate of MACE.

CKD predisposes to higher rate of procedural failure via complex coronary anatomy, derangement of micro vascular structure and function together with a hyper coagulable state leading to a heavier thrombus burden. 


\section{Conclusion:}

CKD is not uncommon finding among patients with STEMI. Both epicardial coronary flow and myocardial perfusion are reduced in CKD patients with STEMI and CKD was independently and inversely associated with the rate of procedural success.

\section{Limitations:}

The study had some limitations. This is a singlecentre experience and represents a limited number of patients.

\section{References}

1- GOODMAN S.G., HUANG W., YAN A.T., et al.: Expanded Global Registry of Acute Coronary Events "GRACE". Am. Heart Journal; 158: 193-201, 2009.

2- FOX C.S., MUNTNER P., CHEN A., et al.: Use of evidence-based therapies in short-term outcomes of STsegment elevation myocardial infarction and non-STsegment elevation myocardial infarction in patients with chronic kidney disease. A report from the National Cardiovascular Data Acute Coronary Treatment and Intervention Outcomes Network Registry. Circulation; 121: 35765, 2010.

3- CHARYTAN D. and KUNTZ R.E.: The exclusion of patients with chronic kidney disease from clinical trials in coronary artery disease. Kidney Int.; 70: 2021-30, 2006.

4- DUMAINE R.L., MONTALESCOT G., STEG P.G., et al.: Reachregistry Investigators. Renal function, atherothrombosis extent, and outcomes in high-risk patients. Am. Heart J.; 158 (1): 141-8, 2009.

5- POLANSKA-SKRZYPCZYK M., KARCZ M., BEKTA P., et al.: Prognostic value of renal function in STEMI patients treated with primary PCI: ANIN Registry. Br. J. Cardiol.; 20: 65, 2013.

6- GENSINI G.G.: A more meaningful scoring system fordetermining the severity of coronary heart disease. Am. J. Cardiol.; 51: 606, 1983.

7- CHESEBRO J.H., KNATTERUD G., ROBERTS R., et al.: Thrombolysis in Myocardial Infarction (TIMI) Trial, Phase I: A comparison between intravenous tissue plasminogen activator and intravenous streptokinase. Clinical findings through hospital discharge. Circulation; 76 (1): 142-54, 1987.

8- VAN 'T HOF A.W., LIEM A., SURYAPRANATA H., et al.: Angiographic Assessment of Myocardial Reperfusion inPatients Treated With Primary Angioplasty for AcuteMyocardial Infarction. Zowellemyocardial infarction study. Circulation; 97: 2302-6, 1998.

9- World Medical Association Declaration of Helsinki: Ethical principle for medical resaerch involving human subjects. J.A.M.A.; 310 (20): 2119-4, 2013.

10-MARENZI G., CABIATI A. and ASSANELLI E.: Chronic kidney disease in acute coronary syndromes. World Journal of Nephrology; 1 (5): 134-45, 2012.
11- WEINSTEIN J.R. and ANDERSON S.: The aging kidney: Physiological changes. Advances in chronic kidney disease; 17 (4): 302-7, 2010.

12- KIM J.Y., JEONG M.H., AHN Y.K., et al.: Decreased Glomerular Filtration Rate is an Independent Predictor of In-Hospital Mortality in Patients With ST-Segment Elevation Myocardial Infarction Undergoing Primary Percutaneous Coronary Intervention. Korean Circulation Journal; 41 (4): 184-90, 2011.

13- LEVEY A.S., JUAN P.B., JULIA B.L., et al.: A More Accurate Method To Estimate Glomerular Filtration Ratefrom Serum Creatinine: A New Prediction Equation. Annals of Internal Medicine; 130 (6): 461-70, 1999.

14- TEDLA F.M., BRAR A., BROWNE R. and BROWN C.: Hypertension in chronic kidney disease: Navigating the evidence. Int. J. Hypertens; 132405, 2011.

15- BERNS J.S.: Routine Screening for CKD Should Be Done in Asymptomatic Adults. Selectively. Clinical Journal of the American Society of Nephrology; 9 (11): 1988-92, 2014.

16- SOSNOV J., LESSARD D., GOLDBERG R.J., et al.: Differential symptoms of acute myocardial infarction in patients with kidney disease: A community-wide perspective. Am. J. Kidney Dis.; 47: 378-84, 2006.

17- DELUCA A.J., KAPLAN S., ARONOW W.S., et al.: Comparison of prevalence of unrecognized myocardial infarction and of silent myocardial ischemia detected by a treadmill exercise sestamibi stress test in patients with versus without diabetes mellitus. Am. J. Cardiol.; 98: 1045-6, 2006.

18- HERZOG C.A., LITTRELL K., ARKO C., et al.: Clinical characteristics of dialysis patients with acute myocardial infarction in the United States: A collaborative project of the United States Renal Data System and the National Registry of Myocardial Infarction. Circulation; 116: 146572, 2007.

19- YAGI H., KAWAI M., KOMUKAI K., et al.: Impact of chronic kidney disease on the severity of initially diagnosed coronary artery disease and the patient prognosis in the Japanese population. Heart Vessels.; 26: 370-8, 2011.

20- COSKUN U., ORTA KILICKESMEZ K., ABACI O., et al.: The relationship between chronic kidney disease and SYNTAX score. Angiology; 62: 504-8, 2011.

21- SABROE L., NISTOR I. and COVIC A.: Heart Failure in Patients with Chronic Kidney Disease: A Systematic Integrative Review. Bio. Med. Research International; 2014: 937398, 2014.

22- KURTUL M., MONTALESCOT G., STEG G., et al.: Renal function, atherothrombosis extent, and outcomes in high-risk patients with no reflow phenomena. Am. Heart J.; 158: 141-8, 2009.

23- CELIK T., IYISOY A., YUKSEL C.U., et al.: Impact of admission glomerular filtration rate on the development of poor myocardial perfusion after primary percutaneous intervention in patients with acute myocardial infarction. Coron. Artery. Dis.; 19 (8): 543-9, 2009. 


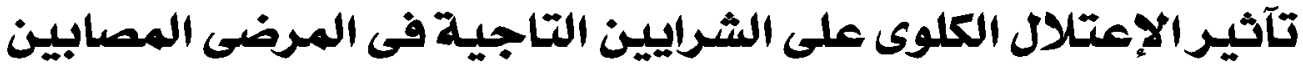

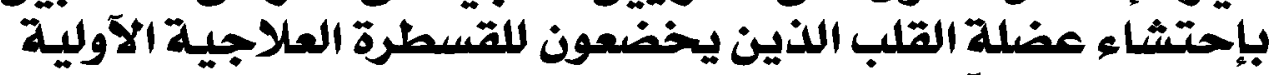 وتآثيره على فترة التواجد بالفون لمستشفى}

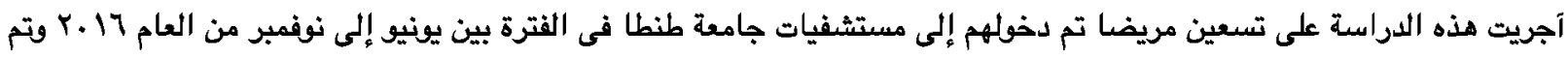

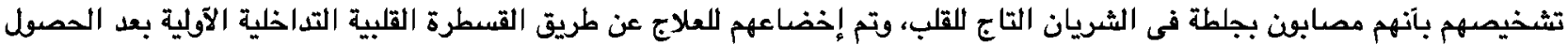
على الموافقة تم تقسيم المرضى بعد حساب وظائف الكلى إلى آريع مجموعات.

وقد لوحظ علم وجود إختلاف ذو دلالة إحصائية فى العلامات الحيوية والمقت من ساعة الدخول حتى إعادة التروية بين المجموعات المختلة،

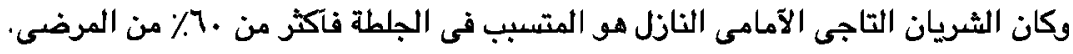

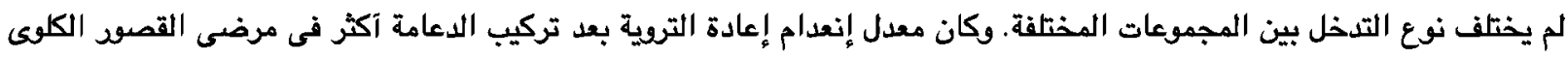

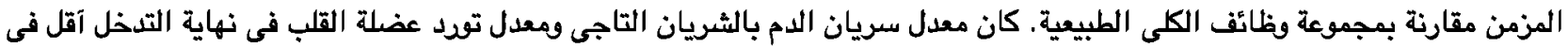

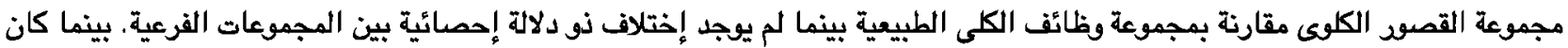

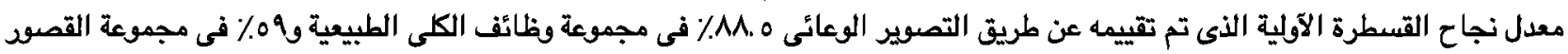
المزمن بوظائف الكلى ولم يوجد فرق نو دلالة إحصائية بين المجموعات الفئ الفرعية.

وكان معدل النجاح متمثلا فى إنخفاض قطعة س-تبعد ع ساعات من التخل آقل في مجموعة القصود المزمن بوظائف الكلى (TV/\%) مقارنة

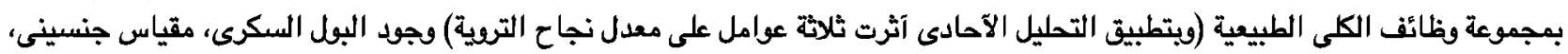

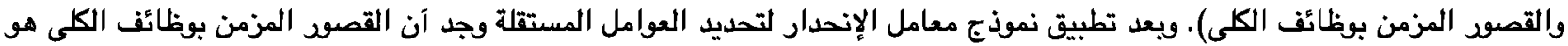

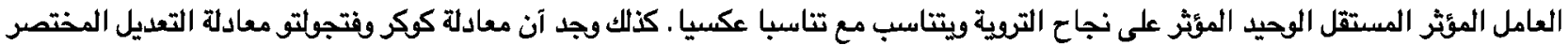

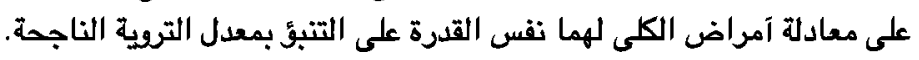

